MISS MARLIES VERKADE (Orcid ID : 0000-0002-0271-8580)

Article type : General Article

\title{
Equine digital tendons show breed specific differences in their mechanical properties that may relate to athletic ability and predisposition to injury
}

M. E. Verkade*a, W. Back ${ }^{\mathrm{a}, \mathrm{b}}$ and H. L. Birch ${ }^{\mathrm{c}}$

${ }^{a}$ Department of Equine Sciences, Faculty of Veterinary Medicine, Utrecht University, Utrecht, The Netherlands; ${ }^{b}$ Department of Surgery and Anaesthesiology, Faculty of Veterinary Medicine, Ghent University, Merelbeke, Belgium and ${ }^{c}$ Department of Orthopaedics and Musculoskeletal Science, University College London, Stanmore Campus, London, UK.

*Corresponding author email: marliesverkade@ hotmail.com

Keywords: horse, tendon, biomechanics, structure-function, breed adaptation.

Running head: Breed specific mechanical equine digital tendon properties

Preliminary results were presented at the British Equine Veterinary Association (BEVA)

Congress, Liverpool, 13-16 September 2017.

\section{Summary}

Background: Throughout the ages, humans have selected horse breeds for their locomotor capacities. Concurrently, tissue properties may have diversified because of specific requirements of different disciplines.

This article has been accepted for publication and undergone full peer review but has not been through the copyediting, typesetting, pagination and proofreading process, which may lead to differences between this version and the Version of Record. Please cite this article as doi: $10.1111 /$ evj. 13169

This article is protected by copyright. All rights reserved. 
Objectives: The aim of this study was to compare the biomechanical properties of tendons with different functions between equine breeds traditionally selected for racing or sport.

Study design: This study used ex vivo tendons and compared the mechanical properties of the common digital extensor tendon (CDET) and superficial digital flexor tendon (SDFT) between racehorses (Thoroughbred $[\mathrm{TB}]$ ) and sports horses (Friesian Horse $[\mathrm{FH}]$, Warmblood [WB]).

Methods: The SDFT and CDET of FH $(n=12)$, WBs $(n=12)$ and TBs $(n=8)$ aged 3-12 years were harvested. The cross sectional area $\left(\mathrm{cm}^{2}\right)$, maximal load $(\mathrm{N})$, ultimate strain $(\%)$, ultimate stress (MPa), and elastic modulus (MPa) were determined and tested for significant differences between the breeds $(\mathrm{P}<0.05)$.

Results: The SDFT from WB horses had a significantly lower elastic modulus than TB horses and failed at a higher strain and load than both FHs and TBs. The mechanical properties of the CDET did not differ between breeds. In agreement with previous studies, the CDET failed at a higher stress and had a higher elastic modulus than the SDFT and, for the WB group of horses only, failed at a significantly lower strain. Interestingly, the mode of failure differed between breeds, particularly with respect to the FHs.

Main limitations: The exercise history of horses used in this study was unknown and the age-range was relatively large; both these factors may have influenced the absolute properties reported in this study.

This article is protected by copyright. All rights reserved. 
Conclusions: This study shows for the first time that mechanical properties of the SDFT differ between breeds. These properties are likely to be related to selection for high-speed versus an extravagant elastic gait and may be an important indicator of performance ability.

\section{Introduction}

Horses have been kept for their impressive locomotor capacities, which developed as a result of limb and tendon elongation in Eohippos 50 million years ago. In 1793, a registry for the breeding of racing Thoroughbreds (TB) was documented. The Friesian horse (FH) is also an ancient pure-bred breed (founded in 1879), whereas the more recently established Warmblood (WB) horses are a mixture of local agricultural working horses and Thoroughbreds. These different breeds can easily be distinguished by eye as they differ in their conformation. It is not known however whether skeletal tissues, such as the digital tendons that play an important role in gait and efficiency of locomotion, also have been altered by selective breeding. The standards of the Friesian studbook require that FHs trot with their heads held high on an upright neck, lifting their front limbs in an upward direction, while WBs move with a lower rounded head carriage and a forward step. These are different kind of gaits to that required by the galloping Thoroughbred.

Tendons are dense, regular connective-tissue structures comprised of a hierarchical arrangement of increasingly larger subunits of collagen [1-7], which are embedded in a glycoprotein matrix [8]. Energy storing tendons, like the superficial digital flexor tendon (SDFT), release elastic energy stored under high tensile stress and strain, resulting in the tendon acting as an elastic spring [9-13]. Positional tendons, like the common digital extensor tendon (CDET), experience lower strains, acting predominantly to transmit muscular force; they need to be relatively inextensible under physiological loads [14-18].

This article is protected by copyright. All rights reserved. 
Competition horses suffer from damage to tendons and ligaments relatively often; the SDFT and suspensory ligament are most frequently affected [12,13,19]. Overtraining, acute trauma and a unbalanced conformation of the horse, as well as tendon tissue quality all play an important role in the occurrence of tendon and ligament injuries. The type of sport and the actual performance level are associated with different anatomical sites of tendon injuries [19]. Recent studies observed that FHs had significantly fewer SDFT injuries than Standardbred horses, but significantly more suspensory ligament injuries than WB horses [20]. Therefore, in this study, tendon biomechanical properties were compared between spring-like and positional-type tendon representatives from the TB, FH and WB breeds to determine whether differences could originate from selection for specific locomotor capacities. The hypothesis is that the SDFT in FH and WB horses will show a less stiff nature, compared to the TB horses.

\section{Materials and methods}

\section{Harvested tendons}

The distal parts of the forelimbs of $12 \mathrm{WB}$ horses, $12 \mathrm{FH}$ and $8 \mathrm{~TB}$ horses were obtained from an abattoir and a veterinary clinic where the horses were euthanised for reasons other than tendon injuries. The age of the horses ranged from 3-12 years.

The forelimbs were frozen and stored at $-20^{\circ} \mathrm{C}$ until the collection of the tendon samples. For the collection of the tendon samples, the limbs were thawed in water of $15^{\circ} \mathrm{C}$. The tendon samples of the CDET and SDFT were obtained from the distal carpus region to metacarpophalangeal region, resulting in tendon samples with a length of approximately 20 $\mathrm{cm}$. The tissue samples were stored frozen at $-20^{\circ} \mathrm{C}$ and transported on dry ice to the testing laboratory.

This article is protected by copyright. All rights reserved. 


\section{Biomechanical testing}

Measurement of cross sectional area (CSA)

The CSA was measured using a technique developed by Goodship and Birch [23]. Aqueous rapid-curing alginate dental impression paste was used to create a mould of the midmetacarpal region of the tendon (Fig 1). A slit was cut through the mould along the tendon and the tendon was removed. A transverse section was taken from the alginate mould and photographed alongside a calibration scale. Digital images were used to measure the area of the hole left by the tendon in the paste using image analysis software ${ }^{\mathrm{a}}$ in an automated procedure. The results are given in $\mathrm{cm}^{2}$.

\section{Tendon mechanical testing}

The biomechanical properties of the tendons were determined using a hydraulic materials testing machine ${ }^{b}$. Cryoclamps cooled with liquid $\mathrm{CO}$ were used to fixate the tendons in a vertical position. The distance between the clamps was $7 \mathrm{~cm}$ to $10 \mathrm{~cm}$ depending on the length of the tendon. The tendons were preloaded with $100 \mathrm{~N}$ (SDFT) or $25 \mathrm{~N}$ (CDET) (approximately 1-2\% of the failure load) and the distance between the frost lines was measured to determine the effective gauge length. Tendons were preconditioned to reach a steady state using 20 cycles of a sine-wave load between 0 and $5.25 \%$ strain at a frequency of $0.5 \mathrm{~Hz}$, returning back to the pre-load [15]. Following preconditioning the pre-load was removed and the tendons were loaded using a ramp load to failure at a strain rate of $80 \% / \mathrm{s}$. Extension and force data were collected at $4 \mathrm{~ms}$ intervals. The location of tendon ruture (top, middle, bottom) and mode of failure were recorded. The resting length was determined from the data by identifying the point at which load on the tendon began to show a steady increase. A stress/strain curve was plotted and the point at which the linear gradient of the curve reached a maximum was identified. Two data points on either side of the maximum were 
included to determine the elastic modulus. The force at failure (N), ultimate stress (MPa), failure strain (\%) and linear elastic modulus (MPa; maximum of stress/strain) were calculated for each tendon.

\section{Data analysis}

The data were analysed for statistical differences using SPSS (version 24) ${ }^{\mathrm{d}}$. A linear mixed model was used including the horse as a subject variable with the tendons and breed as fixed factors. The individual subgroups were compared separately using a Bonferroni post hoc test, if the breed $\mathrm{x}$ tendon showed an interaction. To test for a significant difference in age between the groups an ANOVA test was used. A Chi-square test was performed to determine significant differences in the mode of failure. The significance level was set at $\mathrm{P}<0.05$ for all statistical analyses. All results are given as mean \pm standard deviation (s.d.).

\section{Results}

The data were retrieved from all tendons and the differences between SDFT and CDET and differences between the three breeds are shown in Table 1. There was no significant difference in age between the three breeds (WB 8.83 years \pm 2.40 , FH 8.75 years \pm 2.59 , TB 7.0 years \pm 2.72 ).

\section{Cross-sectional Area}

The SDFT had a significantly larger CSA than the CDET $(\mathrm{P}<0.001)$. There was no significant difference in the CSA of the SDFT between the breeds. For the CDET, the CSA of WBs was significantly larger than that of TBs $(\mathrm{P}=0.009)$.

This article is protected by copyright. All rights reserved. 


\section{Maximal load}

The SDFT showed a significantly greater maximal load than the CDET $(\mathrm{P}<0.001)$. There was also a significant difference between the breeds. The maximal load of the WB SDFT was significantly greater $(\mathrm{P}=0.02)$ than that of the FHs and TBs. The CDET showed no significant difference between the breeds. The tendons of WB horses showed the greatest maximal load, followed by those of FHs and TBs.

\section{Ultimate strain}

There was no significant difference in ultimate strain between the SDFT and CDET for FHs and TBs. In WBs, the ultimate strain of the SDFT was significantly higher than that of the CDET $(\mathrm{P}<0.001)$. The ultimate strain of the SDFT also significantly differed between the breeds. The WB SDFT had a significantly higher $(\mathrm{P}=0.02)$ ultimate strain than that of the FHs and TBs. There was no significant difference for the CDET between the different breeds.

\section{Ultimate stress}

The CDET had a significantly higher ultimate stress level than the SDFT $(\mathrm{P}=0.006)$. There were no significant differences between the different breeds for either tendon type. As seen in Table 1, the ultimate stress of the FH CDET varied widely within the group.

\section{Elastic modulus}

The SDFT had a significantly lower elastic modulus than the CDET $(\mathrm{P}=0.004)$. The elastic modulus did not differ significantly between breeds for the CDET however the SDFT had a significantly higher elastic modulus in the TBs compared to the WBs $(\mathrm{P}=0.009)$. The elastic modulus of the SDFT in FHs did not differ to the TBs or WBs. Typical stress/strain curves for differences between the SDFT and CDET and differences between the three breeds are shown in Figure 2.

This article is protected by copyright. All rights reserved. 


\section{Region of rupture}

The mode of failure appeared to differ between breeds. In the TBs all tendons 'snapped' giving a clean break (Fig 3, Supplementary Item 1). In the FHs the tendon failure occurred mostly by sliding of fascicles/fibres relative to each other (Fig 3, Supplementary Item 2). This difference was significantly different between the breeds (SDFT, $\mathrm{P}=0.05$; CDET, $\mathrm{P}=0.04$, Fig 4)

\section{Discussion}

The results of this study are in agreement with previous studies showing a difference in mechanical properties between the energy storing SDFT and positional CDET $[15,18]$. The SDFT showed a significantly lower material stiffness and the tendon tissue failed at a lower force compared to the CDET tissue and this was consistent across all three breeds studied.

Interestingly, and partially supporting the hypothesis, this study shows for the first time to our knowledge, a breed specific difference between tendons. These differences were seen in the SDFT and were not apparent in the less specialised CDET, other than a larger CSA of the CDET in WB horses. Furthermore, these differences were most exaggerated when comparing the TB horses with the WBs. In WB horses the SDFT had a significantly lower elastic modulus and failed at a significantly higher strain than the SDFT in the TB group of horses. Previous studies using a mix of horse breeds $[15,18]$ have shown a significantly higher ultimate strain for the SDFT compared to the CDET, however in the present study this difference was only significant for the WB horses.

This article is protected by copyright. All rights reserved. 
The higher elastic modulus of the TB SDFT is a characteristic of a stiffer tendon and may relate to the type of activity racehorses undertake. Racehorses are required to exercise regularly at high speeds in a mainly straight line during training and racing. The relatively stiff tendons compared to sports horse breeds can transfer the muscle forces quicker and more efficiently, so more elastic energy can be stored within a shorter ground contact period while keeping an efficient propulsive phase [15,24-26].

A lower elastic modulus resulting in a less stiff SDFT in the WB horses supports the hypothesis that sports horse breeds have more compliant elastic tendons to fulfil their locomotion requirements. Sports horses are trained differently at much lower speeds, therefore their tendons require different properties to adapt to these types of exercise. The take off for jumping a fence, for example, is relatively slow, which gives the more easily extended tendon time to store and release energy. Besides that, jumping a fence causes (extreme) hyperextension of the metacarpo-/metatarso-phalangeal joints. Landing after a jump significantly increases the forelimb ground reaction force compared to normal canter [27] and the tendons of the forelimbs are subjected to considerable strain and repetitive loading [28]. High level dressage horses are asked to collect their strides, leading to a great proportion of their bodyweight being carried by the hindlimbs. This leads to an increase in stance duration, which might be exaggerated during specific movements such as canter pirouettes, leading to soft tissue injuries [29]. These findings support the hypothesis that different tendon properties are required to perform the specific movements in different sport activities.

This article is protected by copyright. All rights reserved. 
Although there is now considerable evidence to support a difference in biomechanical properties between functionally distinct tendons, the mechanisms conferring these different properties on the tendon are less well understood. The energy storing SDFT has been shown to have a less stiff interface between the tendon fascicles than the CDET, enabling a greater fascicle sliding that could account for increased failure strain in the SDFT [18,30]. It may be that this adaptation is amplified in the SDFT of WB horses accounting for the lower elastic modulus and higher ultimate strain reported in this study. Differences between the SDFT and CDET in biochemical composition have also been reported [16]. The SDFT has a higher water content, higher sulphated glycosaminoglycan content, smaller collagen fibril diameters and a different collagen crosslink profile when compared to the CDET [16]. Levels of pyrrole, although a minor crosslink in tendon, show a significant positive correlation with tendon yield stress, ultimate stress and elastic modulus in the SDFT [12]. Furthermore, the rate of turnover of the collagen and non-collagenous components differs significantly between the SDFT and CDET tissue [31]. The link between these matrix differences and biomechanical behaviour is not yet fully understood but may also operate within the SDFT from different breeds.

The breed specific differences in tendon properties reported in our study may also contribute towards the different pattern of tendon injuries seen in different disciplines. In TB racehorses the SDFT is most often injured. In a study of National Hunt racehorses over two seasons of racing the SDFT accounted for $89 \%$ of all tendon and ligament injuries [32]. In elite event horses (intermediate level and above), where TB horses are most numerous, a study of orthopaedic injuries showed that injuries are most likely to be to the SDFT [19]. It may be that lower ultimate strains values recorded in our study for the TB SDFT predispose to overstrain injury. In contrast, in dressage horses where WB horses dominate, suspensory ligament

This article is protected by copyright. All rights reserved. 
injuries in the hind limbs are more common $[19,22,33,34]$. There is also a reported increased risk of suspensory ligament injuries in FH [20,21], which besides the required 'dressage' movements, may also be amplified by the already hyperextended position of the metacarpophalangeal joints in FH [35-37]. Although these studies report significant differences in tendon injuries related to their locomotor performance, none of the studies investigated differences in biomechanical tendon properties that could possibly lead to these injuries.

An unexpected finding but one that might be highly relevant to tendon injury in the FH, was the difference in the way tendons ruptured in the failure test. The FH tendons tended to undergo excessive stretching with fibres sliding past each other rather than showing a clean break as seen in the TB tendons and the majority of WB tendons. There is evidence from studies investigating aortic rupture and megaoesophagus in FHs to suggest a genetic mutation that causes collagen in tissues to clump and become disorganised [36-38]. A different distribution of collagen in FH tendons might be an explanation for the difference in rupture pattern compared with the other breeds.

The results of the study are intriguing, however there are a number of limitations that should be considered. Although all horses were skeletally mature, the age-range studied was relatively large. Furthermore the activity type and level of the horses in the study was unknown. Both these factors may have influenced the tendon properties reported in this study.

This article is protected by copyright. All rights reserved. 
In conclusion, the results of this study have revealed an exciting and previously unrecognised specialisation of the biomechanical properties of the SDFT in horses bred for high speed and stamina versus those bred for power and an extravagant elastic gait. We consider that it is most likely that these properties have evolved through selective breeding for performance over the years. However, it is intriguing to speculate as to whether the SDFT adapts further following exercise and training in a specific discipline and whether this ability to adapt relates to susceptibility to injury. Furthermore, how well evolved or adapted the tendons are for a specific function and discipline may be related to performance and could be used as a selection tool. Unraveling the (genetic) mechanism for these differences is important as it may allow an indirect assessment of tendon mechanical properties in the future.

\section{Authors' declaration of interests}

No competing interests have been declared.

\section{Ethical animal research}

The study was conducted on cadaver tissue from the local abattoir, so no approval from an ethical committee was necessary.

\section{Owner informed consent}

Not applicable.

\section{Data accessibility statement}

The data that support the findings of this study are available on request from the corresponding author.

This article is protected by copyright. All rights reserved. 


\section{Sources of funding}

No sources of funding were used.

\section{Acknowledgements}

We would like to thank Joke Verkade, Jan van Dasselaar and Ab van Dijk with their help collecting the limbs. We would also like to thank H. Vernooij for his advice on the statistical analysis.

\section{Authorship}

M. Verkade and H. Birch were responsible for the study design, study execution, data analysis and interpretation, preparation of the manuscript and final approval of the manuscript. W. Back contributed to the study design, data analysis and interpretation, preparation of the manuscript and final approval of the manuscript.

\section{Manufacturers' addresses}

${ }^{1}$ Image-Pro Plus, Media Cybernetics, Inc., Rockville, Maryland, USA.

${ }^{2}$ Zwick Testing Machines Ltd, Leominster, Herefordshire, UK.

${ }^{3}$ Ms Excel, Office 2010, Microsoft, Seattle, USA.

${ }^{4}$ IBM Corp. Released 2015. IBM SPSS Statistics for Windows, Version 24.0. Armonk, New York, USA.

This article is protected by copyright. All rights reserved. 
Table 1: Biomechanical variables (mean \pm s.d.) in three breeds of horses.

\begin{tabular}{|c|c|c|c|c|}
\hline $\begin{array}{l}\text { Biomechanical } \\
\text { parameters }\end{array}$ & Tendon & $\begin{array}{l}\text { Warmblood } \\
(n=12)\end{array}$ & $\begin{array}{l}\text { Friesian } \\
(n=12)\end{array}$ & $\begin{array}{l}\text { Thoroughbred } \\
\qquad(n=8)\end{array}$ \\
\hline \multirow{2}{*}{$\begin{array}{c}C S A \\
\left(\mathrm{~mm}^{2}\right)\end{array}$} & SDFT & $110.7 \pm 27.5$ & $93.4 \pm 16.9$ & $89.0 \pm 26.3$ \\
\hline & CDET & $37.0 \pm 7.7^{*}$ & $31.2 \pm 2.8$ & $26.2 \pm 7.3$ \\
\hline \multirow{2}{*}{$\begin{array}{l}\text { Maximal Load } \\
\text { (N) }\end{array}$} & SDFT & $12606 \pm 1936^{\S}$ & $10101 \pm 1583$ & $9982 \pm 3446$ \\
\hline & CDET & $5583 \pm 971$ & $4939 \pm 976$ & $4332 \pm 1229$ \\
\hline \multirow{2}{*}{ Ultimate strain (\%) } & SDFT & $32.6 \pm 6.0^{\circ \S}$ & $26.4 \pm 4.1$ & $25.3 \pm 4.6$ \\
\hline & CDET & $20.5 \pm 4.7$ & $21.4 \pm 5.6$ & $21.5 \pm 4.5$ \\
\hline \multirow{2}{*}{$\begin{array}{l}\text { Ultimate stress } \\
(\mathrm{MPa})\end{array}$} & SDFT & $116.9 \pm 17.8$ & $110.4 \pm 20.6$ & $121.4 \pm 18.6$ \\
\hline & CDET & $153.3 \pm 21.4$ & $160.5 \pm 38.7$ & $171.9 \pm 50.2$ \\
\hline \multirow{2}{*}{$\begin{array}{c}\text { Modulus } \\
\text { (stress/strain MPa) }\end{array}$} & SDFT & $397.3 \pm 87.1^{*}$ & $507.7 \pm 141.4$ & $595.7 \pm 100.1$ \\
\hline & CDET & $971.0 \pm 131.1$ & $929.6 \pm 129.3$ & $1012.6 \pm 163.8$ \\
\hline
\end{tabular}

* denotes a significant difference compared to Thoroughbred horses $(\mathrm{P}<0.05) ; \S$ denotes a significant difference relative to Friesian horses $(\mathrm{P}<0.05)$

Bold: superficial digital flexor tendon (SDFT) significantly different from common digital extensor tendon (CDET; $\mathrm{P}<0.05)$.

\section{Figure legends}

Fig 1: An alginate paste mould of a tendon using a calibration scale to calculate the cross sectional area $(\mathrm{CSA})$ of the tendon.

Fig 2: a) Typical stress/strain curve of a WB SDFT (orange) and CDET (blue). b) Typical stress/strain curve of the SDFT of the three breeds ( $\mathrm{WB}=$ blue; $\mathrm{FH}=$ orange; $\mathrm{TB}=$ grey).

Fig 3: Photographic illustration of the difference in breaking mode of Friesian (top; a,b) and Thoroughbred (bottom; c,d) superficial digital flexor tendons (SDFT). Tendons are shown at the point of rupture (left; a, c) and following rupture as the clamps continue to move apart

This article is protected by copyright. All rights reserved. 
(right; b,d). The Friesian tendon ruptured in the core, leaving the outer fibres stretched but intact, whereas the Thoroughbred tendons showed an almost clean break.

Fig 4: A bar graph providing an overview of the percentage of the total number of superficial digital flexor tendon (SDFT) and common digital extensor tendons (CDET) that were partially stretched (light blue) rather than fully snapped (dark blue) ( 60\% of Friesian CDET, $\sim 40 \%$ of Warmblood CDET and $\sim 30 \%$ of Friesian SDFT; all Thoroughbred tendons snapped).

\section{Supporting Information}

Supplementary Item 1: Rupture pattern Thoroughbred superficial digital extensor tendon (SDFT).

Supplementary Item 2: Rupture pattern Friesian superficial digital extensor tendon (SDFT).

\section{References}

1. Kastelic, J., Galeski, A. and Baer, E. (1978) The multicomposite structure of tendon. Connect. Tissue Res. 6, 11-23.

2. Tsuzaki, M., Yamauchi, M. and Banes, A.J. (1993) Tendon collagens: Extracellular matrix composition in shear stress and tensile components of flexor tendons. Connect. Tissue Res. 29, 141-152.

3. Crevier, N., Pourcelot, P., Denoix, J.M., Geiger, D., Bortolussi, C., Ribot, X. and Sanaa, M. (1996) Segmental variations of in vitro mechanical properties in equine superficial digital flexor tendons. Am. J. Vet. Res. 57, 1111-1117.

This article is protected by copyright. All rights reserved. 
4. Kjær, M. (2004) Role of Extracellular Matrix in Adaptation of Tendon and Skeletal Muscle to Mechanical Loading. Physiol. Rev. 84, 649-698.

5. Wang, J.H. (2006) Mechanobiology of tendon. J. Biomech. 39, 1563-1582.

6. Thorpe, C.T., Riley, G.P., Birch, H.L., Clegg, P.D. and Screen, H.R.C. (2014) Effect of fatigue loading on structure and functional behaviour of fascicles from energy-storing tendons. Acta Biomaterialia. 10, 3217-3224.

7. Birch, H.L., Wilson, A.M. and Goodship, A.E. (2008) Physical activity: Does long-term, high-intensity exercise in horses result in tendon degeneration? J. Appl. Physiol. 105, 1927-1933.

8. Kannus, P. (2000) Structure of the tendon connective tissue. Scand. J. Med. Sci. Sports. 10, 312-320.

9. Wilmink, J., Wilson, A.M. and Goodship, A.E. (1992) Functional significance of the morphology and micromechanics of collagen fibres in relation to partial rupture of the superficial digital flexor tendon in racehorses. Res. Vet. Sci. 53, 354-359.

10. Kirkendall, D.T. and Garrett, W.E. (1997) Function and biomechanics of tendons. Scand. J. Med. Sci. Sports. 7, 62-66.

11. Wilson, A.M., McGuigan, M.P., Su, A. and van den Bogert, A.J. (2001) Horses damp the spring in their step. Nature 414, 895-899.

12. Thorpe, C.T. Stark, R.J., Goodship, A.E. and Birch, H.L. (2010) Mechanical properties of the equine superficial digital flexor tendon relate to specific collagen cross-link levels. Equine Vet. J. 42, 538-543.

This article is protected by copyright. All rights reserved. 
13. Souza, M.V. van Weeren, P.R., van Schie, H.T. and van de Lest, C.H. (2010) Regional differences in biochemical, biomechanical and histomorphological characteristics of the equine suspensory ligament. Equine Vet. J. 42, 611-620.

14. Riemersma, D.J. and De Bruyn, P. (1986) Variations in cross-sectional area and composition of equine tendons with regard to their mechanical function. Res. Vet. Sci. 41, 7-13.

15. Batson, E.L., Paramour, R.J., Smith, T.J., Birch, H.L., Patterson-Kane, J.C. and Goodship, A.E. (2003) Are the material properties and matrix composition of equine flexor and extensor tendons determined by their functions? Equine Vet. J. 35, 314-318.

16. Birch, H.L. (2007) Tendon matrix composition and turnover in relation to functional requirements. Int. J. Exp. Pathol. 88, 241-248.

17. Dowling, B.A. and Dart, A.J. (2005) Mechanical and functional properties of the equine superficial digital flexor tendon. The Vet J. 170, 184-192.

18. Thorpe, C.T., Udeze, C.P., Birch, H.L., Clegg, P.D. and Screen, H.R. (2012) Capacity for sliding between tendon fascicles decreases with ageing in injury prone equine tendons: A possible mechanism for age-related tendinopathy? European Cells \& Materials. 25, 4860.

19. Murray, R.C., Dyson, S.J., Tranquille, C. and Adams, V. (2006) Association of type of sport and performance level with anatomical site of orthopaedic injury diagnosis. Equine Vet. J. 38, Suppl. 36, 411-416.

20. Van Riet, M.I., Van den Belt, A.J.M. and Back, W. (2013) Retrospective study of tendon and ligament distal limb injuries detected using ultrasound in Friesian horses admitted to

This article is protected by copyright. All rights reserved. 
an university hospital (2002-2012). Proc. Voorjaarsdagen Congress, Amsterdam, The Netherlands. 2.

21. Brommer, H., Voermans, M., Veraa, S., Van den Belt, A.J.M., Van der Toorn, A., Ploeg M, Gröne, A. and Back, W. (2014) Axial osteitis of the proximal sesamoid bones and desmitis of the intersesamoidean ligament in the hindlimb of Friesian horses: Review of 12 cases (2002-2012) and post-mortem analysis of the bone-ligament interface. $B M C$ Vet. Res. 10, 10.1186/s12917-014-0272-x

22. Van den Belt, A.J.M., Dik, K.J. and Barneveld, A. (1994) Ultrasonographic evaluation and long-term follow-up of flexor tendonitis/desmitis in the metacarpal/metatarsal region in Dutch warmblood horses and standardbred racehorses. Vet. Q. 16, Suppl. 2, S76-80.

23. Goodship, A.E. and Birch, H.L. (2005) Cross sectional area measurement of tendon and ligament in vitro: A simple, rapid, non-destructive technique. J. Biomech. 38, 605-608.

24. Biewener, A.A. (1998) Muscle-tendon stresses and elastic energy storage during locomotion in the horse. Comp. Biochem. Physiol. B. Biochem. Mol. Biol. 120, 73-87.

25. Alexander, R. (1988) Elastic Mechanisms in Animal Movement. Cambridge University Press.

26. Harrison, S.M., Whitton, R.C., Kawcak, C.E., Stover, S.M. and Pandy, M.G. (2010) Relationship between muscle forces, joint loading and utilization of elastic strain energy in equine locomotion. J. Exp. Biol. 213, 3998-4009.

27. Schambardt, H.C., Merkens, H.W., Vogel, V. and Willekens, C. (1993) External loads on the limbs of jumping horses at take-off and landing. Am. J. Vet. Res. 54, 675-680.

This article is protected by copyright. All rights reserved. 
28. Meershoek, L.S., Schamhardt, H.C., Roepstorff, L. and Johnston, C. (2001) Forelimb tendon loading during jump landings and the influence of fence height. Equine Vet. J. 33, 6-10.

29. Burns, T.E. and Clayton, H.M. (1997) Comparison of the temporal kinematics of the canter pirouette and collected canter. Equine Vet. J. 29, 58-61.

30. Thorpe, C.T., Godinho, M.S.C., Riley, G.P., Birch, H.L., Clegg, P.D. and Screen, H.R.C. (2015) The interfascicular matrix enables fascicle sliding and recovery in tendon, and behaves more elastically in energy storing tendons. J. Mech. Behav. Biomed. Mater. 52, 85-94.

31. Thorpe, C.T., Streeter, I., Pinchbeck, G.L., Goodship, A.E., Clegg, P.D. and Birch, H.L. (2010) Aspartic Acid Racemization and Collagen Degradation Markers Reveal an Accumulation of Damage in Tendon Collagen That Is Enhanced with Aging. J. Biol. Chem. 285, 15674-15681.

32. Ely, E.R., Avella, C.S., Price, J.S., Smith, R.K.W., Wood, J.L.N. and Verheyen, K.L.P. (2009) Descriptive epidemiology of fracture, tendon and suspensory ligament injuries in National Hunt racehorses in training. Equine Vet. J. 41, 372-378.

33. Dyson, S. (2002) Lameness and poor performance in the sport horse: Dressage, show jumping and horse trials. J. Equine Vet. Sci. 22, 145-150.

34. Crişan, M.I., Damian, A., Ştefănuţ, L.C., Dezdrobitu, C.C., Neagu, D.M. and Denoix, J. (2018) Global Epidemiological Analysis of Prevalence and Risk Factors Associated with the Deep Digital Flexor Tendinopathy in the Equine Distal Limb: 100 Cases. J. Equine Vet. Sci. 67, 55-60.

This article is protected by copyright. All rights reserved. 
35. Van den Belt, A.J.M., Becker, C.K. and Dik, K.J. (1993) Desmitis of the accessory ligament of the deep digital flexor tendon in the horse: clinical and ultrasonographic features. A report of 24 cases. Zentralblatt für Veterinärmedizin, Reihe A: Anatomie, Histologie, Entwicklungsgeschichte, Physiologie, Biochemie, Ernährung, Pharmakologie, Klinik, Tierzucht, Pathologie. 40, 492-500.

36. Boerma, S., Back, W. and Sloet, M.M. (2012) The Friesian horse breed: A clinical challenge to the equine veterinarian? Equine Vet. Educ. 24, 66-71.

37. Gussekloo, S.W.S., Lankester, J., Kersten, W. and Back, W. (2011) Effect of differences in tendon properties on functionality of the passive stay apparatus in horses. Am. J. Vet. Res. 72, 474-483.

This article is protected by copyright. All rights reserved. 


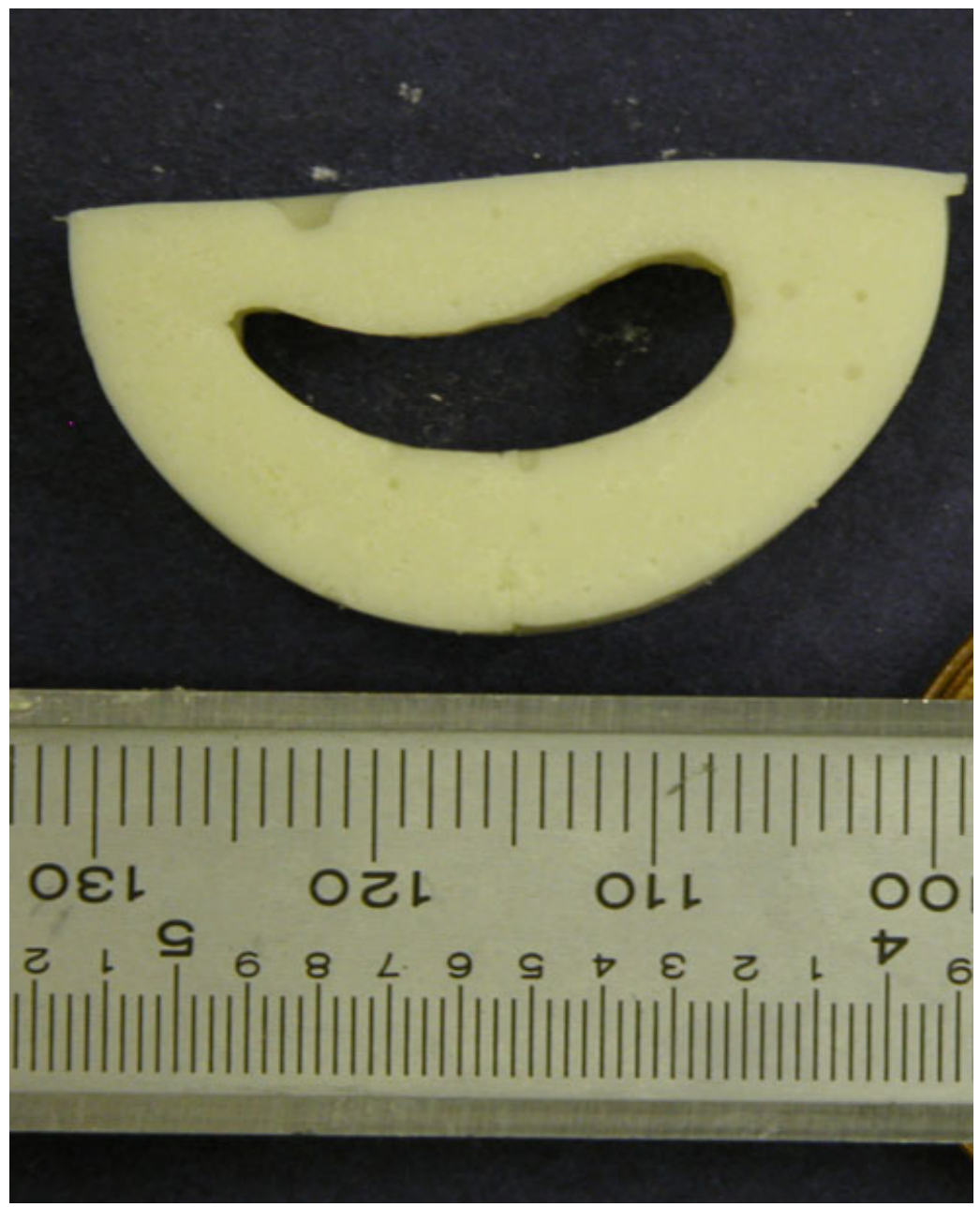

This article is protected by copyright. All rights reserved. 

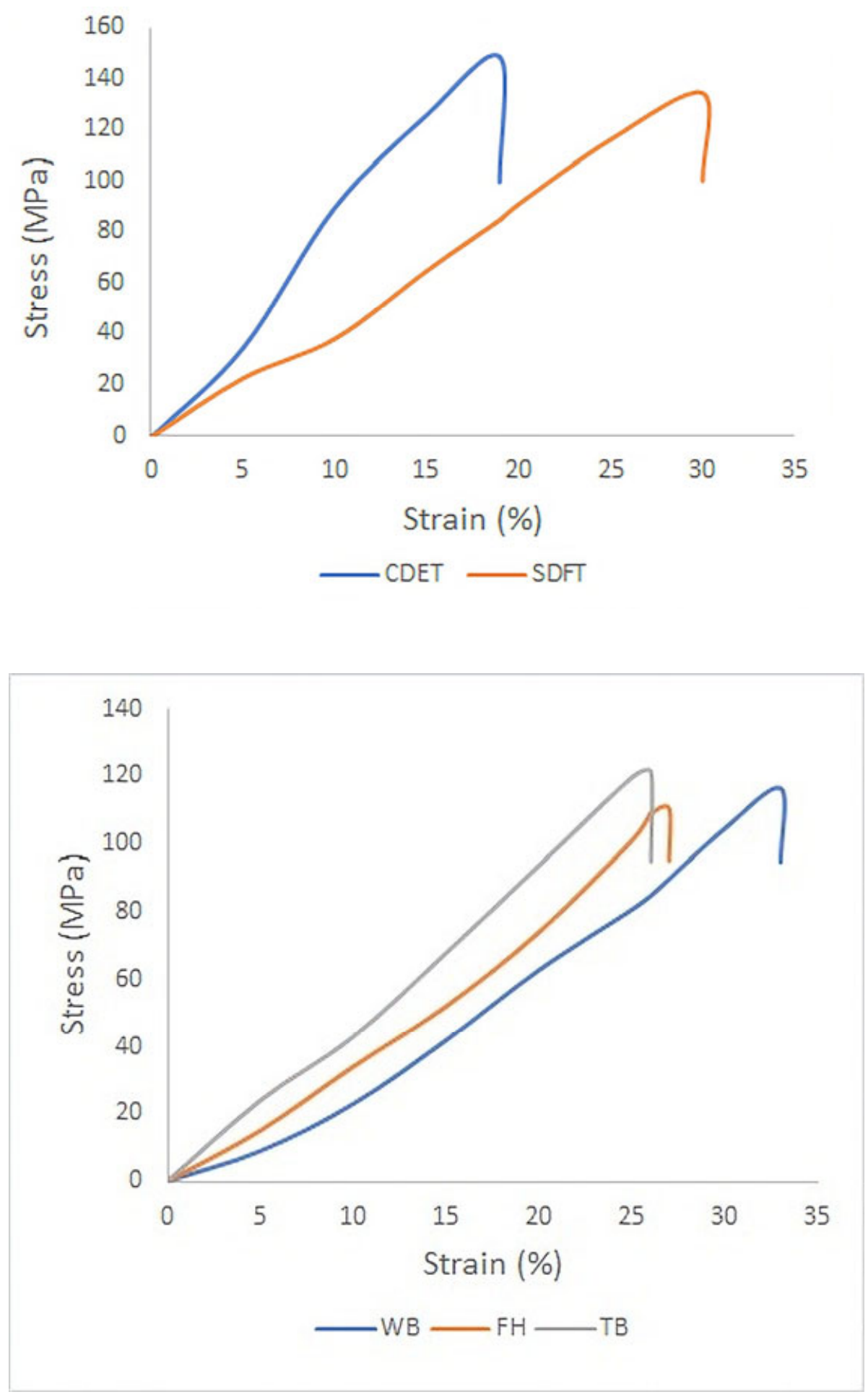

This article is protected by copyright. All rights reserved. 


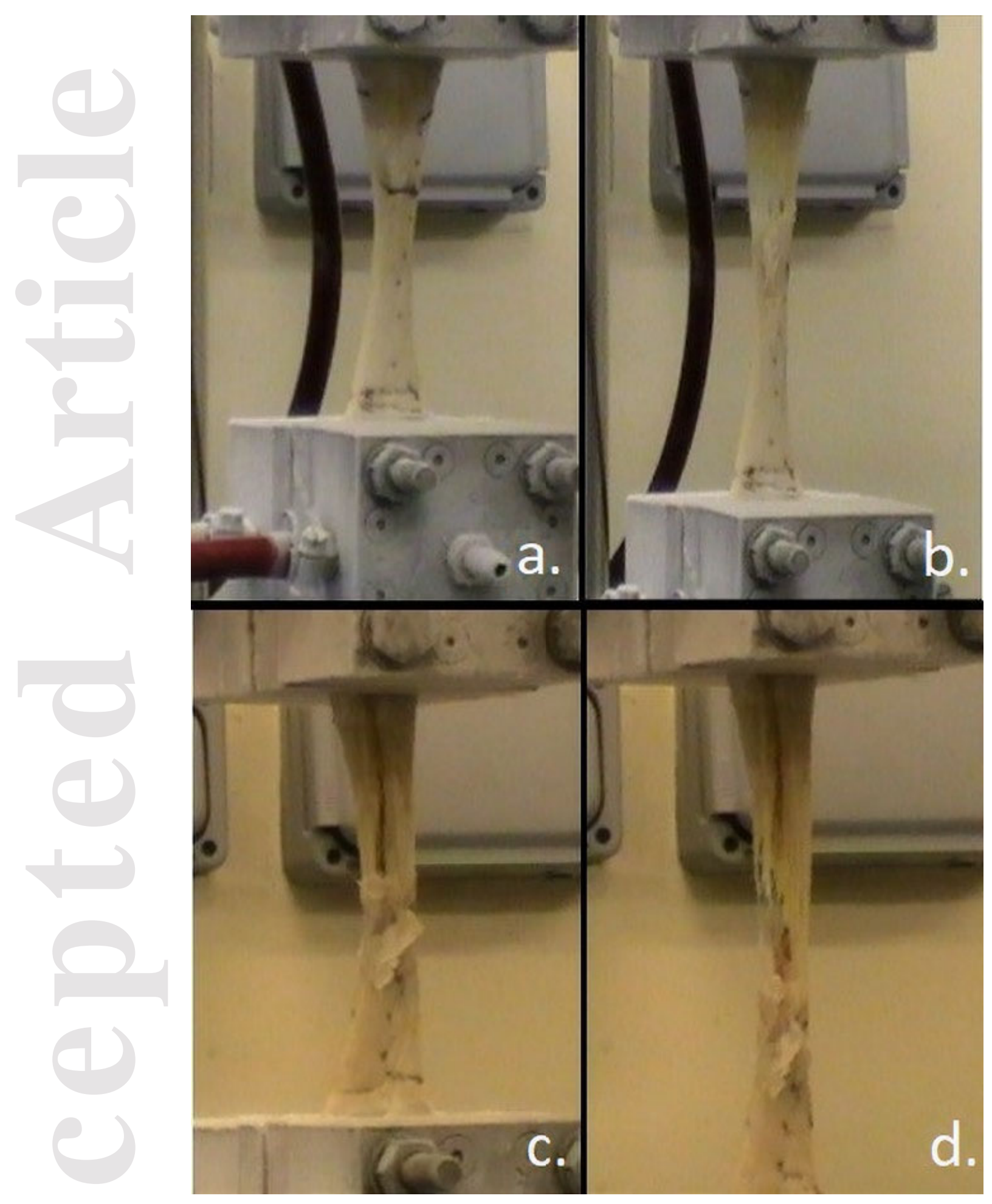




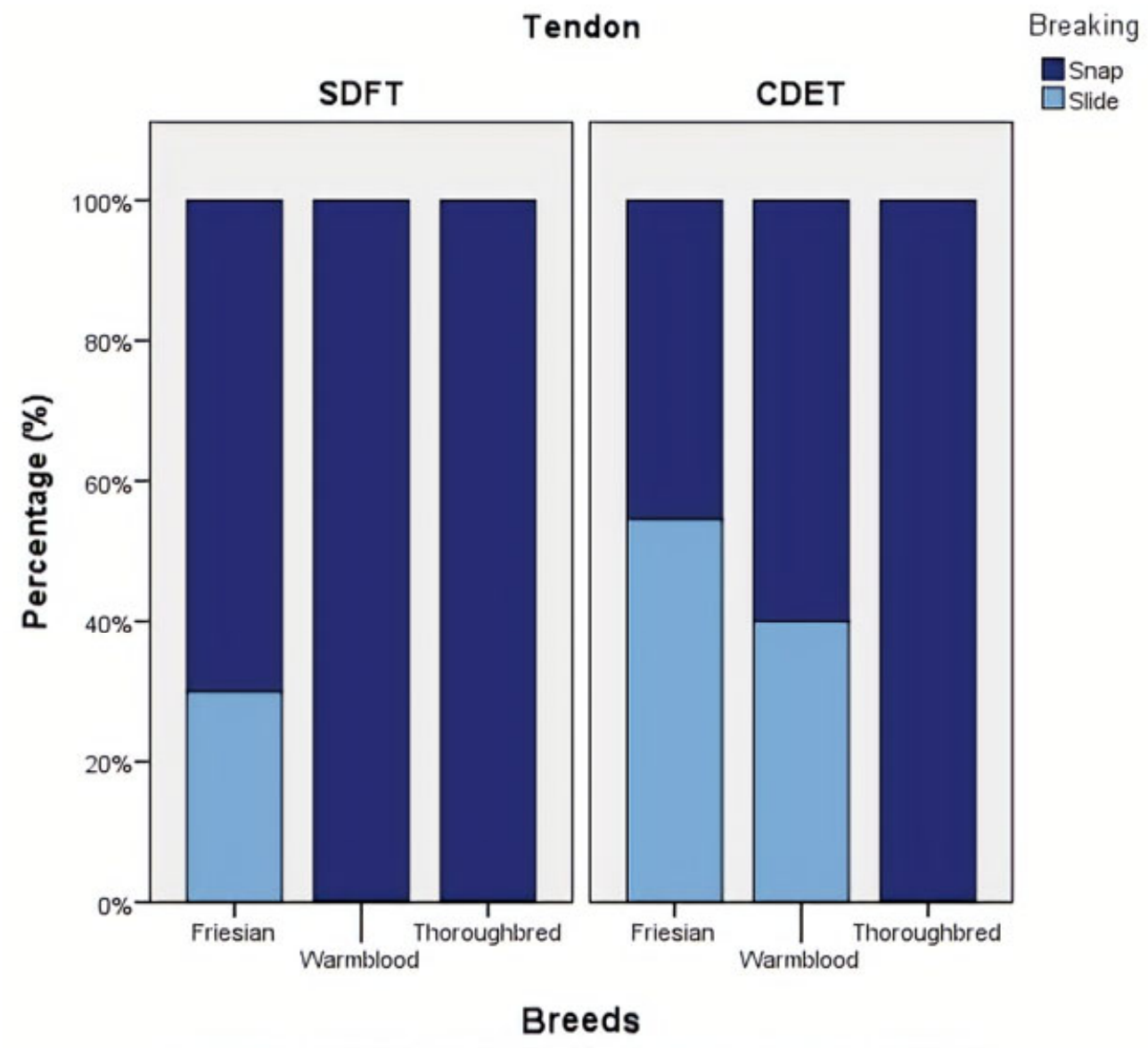

This article is protected by copyright. All rights reserved. 